\title{
Chlamydia caviae in Swiss and Dutch Guinea Pigs-Occurrence and Genetic Diversity
}

\author{
Silvia Ciuria ${ }^{1,2}{ }^{2}$ Michael S. M. Brouwer ${ }^{3}$, Marende M. de Gier ${ }^{4}$, Yvonne van Zeeland ${ }^{4}$, Alex Bossers ${ }^{3}{ }^{\circ}$,

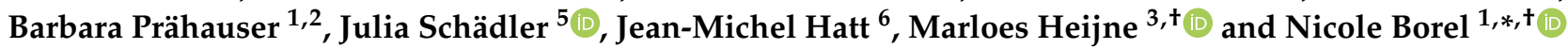 \\ 1 Institute of Veterinary Pathology, Vetsuisse Faculty, University of Zurich, 8057 Zürich, Switzerland; \\ silvia.ciuria@uzh.ch (S.C.); barbara.praehauser@uzh.ch (B.P.) \\ 2 Center for Clinical Studies, Vetsuisse Faculty, University of Zurich, 8057 Zürich, Switzerland \\ 3 Department of Bacteriology, Host-Pathogen Interaction and Diagnostics Development, \\ Wageningen Bioveterinary Research, 8221 RA Lelystad, The Netherlands; \\ mike.brouwer@wur.nl (M.S.M.B.); alex.bossers@wur.nl (A.B.); marloes.heijne@wur.nl (M.H.) \\ 4 Department of Clinical Sciences, Faculty of Veterinary Medicine, Utrecht University, 3584 CM Utrecht, \\ The Netherlands; m.m.degier2@students.uu.nl (M.M.d.G.); y.r.a.vanzeeland@uu.nl (Y.v.Z.) \\ 5 National Reference Centre for Poultry and Rabbit Diseases, Institute for Food Safety and Hygiene, \\ Vetsuisse Faculty, University of Zurich, 8057 Zürich, Switzerland; julia.schaedler2@uzh.ch \\ 6 Clinic for Zoo Animals, Exotic Pets and Wildlife, Vetsuisse Faculty, University of Zurich, \\ 8057 Zürich, Switzerland; jmhatt@vetclinics.uzh.ch \\ * Correspondence: nicole.borel@uzh.ch; Tel.: +41-44-6358563 \\ + These authors contributed equally.
}

check for updates

Citation: Ciuria, S.; Brouwer, M.S.M.; de Gier, M.M.; van Zeeland, Y.; Bossers, A.; Prähauser, B.; Schädler, J.; Hatt, J.-M.; Heijne, M.; Borel, N. Chlamydia caviae in Swiss and Dutch Guinea Pigs-Occurrence and Genetic Diversity. Pathogens 2021, 10, 1230. https://doi.org/10.3390/ pathogens10101230

Academic Editor: Lee Ann Campbell

Received: 5 August 2021

Accepted: 21 September 2021

Published: 23 September 2021

Publisher's Note: MDPI stays neutral with regard to jurisdictional claims in published maps and institutional affiliations.

Copyright: (c) 2021 by the authors. Licensee MDPI, Basel, Switzerland. This article is an open access article distributed under the terms and conditions of the Creative Commons Attribution (CC BY) license (https:/ / creativecommons.org/licenses/by/ $4.0 /)$.

\begin{abstract}
Chlamydia (C.) caviae is a known pathogen in guinea pigs, causing conjunctivitis, respiratory infections and abortions. Recently, a C. caviae-induced zoonotic link was identified as the etiology of severe community-acquired pneumonia in humans. Here, 784 conjunctival and rectal swabs originating from 260 guinea pigs and 110 rabbits from 64 husbandries in Switzerland, as well as 200 composite conjunctival swabs originating from 878 guinea pigs from 37 husbandries in The Netherlands were examined by real-time PCR followed by conventional PCR and sequencing. Chlamydiaceae were detected in 2.3\% (18/784) and 12.5\% (25/200) of all Swiss and Dutch samples, respectively. An overall C. caviae occurrence was detected in $2.7 \%(7 / 260)$ and $8.9 \%(78 / 878)$ of all Swiss and Dutch guinea pigs, respectively. OmpA genotyping of 64 C. caviae-positive samples resulted in 33 sequences sharing 100\% nucleotide identity with the strains isolated from the zoonotic transmission cases in The Netherlands. However, all ompA sequences of this study were distinct from the $C$. caviae GPIC reference strain. C. caviae was not detected in rabbits but $C$. psittaci genotype A was identified in guinea pigs and rabbits, raising concerns about the importance of these animal species as novel zoonotic sources for C. psittaci.
\end{abstract}

Keywords: Chlamydia caviae; Chlamydia psittaci; Chlamydiaceae; Cavia porcellus; Oryctolagus cuniculus; zoonotic potential; genetic diversity; ompA genotyping

\section{Introduction}

The Chlamydiaceae family is composed of one single genus, Chlamydia (C.). This genus includes fourteen different species and several Candidatus species of Gram-negative, obligate intracellular bacteria with a biphasic life cycle [1]. Chlamydiaceae are globally distributed and possess the ability to infect over 400 different hosts, from wildlife to pets and humans, with some chlamydial species considered strictly host-specific, while others are zoonotic [2].

For C. caviae, the main host is the guinea pig (Cavia porcellus). It was first isolated by Murray in 1964 from the conjunctiva of an infected young laboratory guinea pig [3]. In this host, $C$. caviae invades mucosal epithelial cells, particularly of the conjunctiva, as well 
as the lungs, urinary bladder and genital organs [4]. Infections can range from asymptomatic to systemic, with clinical signs such as conjunctivitis (GPIC, guinea pig inclusion conjunctivitis), purulent ocular discharge, chemosis, rhinitis, pneumonia, ascending genital tract inflammation and abortions [1]. Transmission can occur through close contact, vertically and sexually, spreading quickly among animals housed together [5]. Although the clinical signs following C. caviae infection are well known, data on its prevalence is limited. Lutz-Wohlgroth et al. showed a $48 \%(59 / 123)$ prevalence for $C$. caviae in guinea pigs from Switzerland, with $81 \%$ (48/59) of those exhibiting clinical signs [6]. However, these numbers were based on a prevalence study across animals presented with ocular signs at the Ophthalmology Unit of the Department for small animals at the University of Zurich, hence leading to an estimated prevalence within a diseased (sub)population, therefore likely overestimating the actual prevalence of the pathogen. As a result, information regarding $C$. caviae prevalence in healthy guinea pig populations remains scarce, despite their importance as popular companion animals, especially for children.

Several Chlamydia species such as C. abortus and C. psittaci have a well-known zoonotic potential, resulting in severe clinical symptoms in humans, such as atypical pneumonia, abortion and septicemia [7]. For C. caviae, the zoonotic potential was only recently identified. First, Lutz-Wohlgroth et al. retrieved C. caviae in the conjunctival swab of an owner of a diseased guinea pig flock who suffered from mild serous ocular discharge [6]. More recently, three patients in The Netherlands were hospitalized with community-acquired pneumonia with two of them diagnosed with severe respiratory insufficiency requiring mechanical ventilation for several days [8]. C. caviae was the only pathogen detected in the bronchoalveolar fluid of these patients. All three patients reported owning guinea pigs at home or were in contact with them in a veterinary clinic. The guinea pigs likewise showed respiratory signs and conjunctivitis prior to their owners' illness [8]. A fourth patient diagnosed with severe community-acquired pneumonia was $C$. caviae-positive in the bronchoalveolar fluid and feces [9]. This patient did not report any prior guinea pig contact, raising questions about the zoonotic transmission source. In one of the patients in the Ramakers et al. report, the direct transmission from a guinea pig to its owner was confirmed through tandem repeat analysis and sequencing of the outer membrane protein $\mathrm{A}(\mathrm{omp} A)$ coding region as both isolates were identical [8]. In these analyses, the investigated molecular features of the zoonotic strain were different from the $C$. caviae strain GPIC (GenBank accession number: AE015925) but shared homology with two German C. caviae strains (DSM 27655 and 04DC41; with GenBank accession numbers KY777665.1 and KY777667, respectively), raising questions about the molecular epidemiology of C. caviae circulating in the European guinea pig population.

Despite veterinary recommendations not to mix animal species, many husbandries host guinea pigs and rabbits in the same enclosures. This can lead to increased stress, behavioral problems, miscommunication and potential pathogen transmission between these two species $[10,11]$. In general, knowledge on chlamydial infections in rabbits is limited. Historically, Iversen et al. reported an experimental inoculation with C. psittaci strain M56 (originally isolated from muskrats (Ondantra zibethicus) and snowshoe hares (Lepus americanus) in 1961 [12]) in snowshoe hares, which led to a surprisingly high mortality (18 deaths of the 19 exposed lagomorphs) [13]. The infection was shown to be an acute and febrile illness with terminal clinical signs including opisthotonos, convulsions and hypoglycemia [13]. Additional research from Iversen et al. $(1974,1976)$ demonstrated that experimental infections using the same strain in cottontail rabbits (Sylvilagus floridans) and domestic rabbits (Oryctolagus cuniculus) likewise led to a febrile illness, but with greatly diminished lethality and, for the first time, with ocular lesions (i.e., anterior uveitis and conjunctivitis) $[14,15]$. Until Lutz-Wohlgroth et al. reported C. caviae in a conjunctival sample of one rabbit exhibiting mild ocular discharge, no further research was done on this topic [6]. Lately, Ni et al. showed a Chlamydia seroprevalence of $17.9 \%(143 / 800)$ in domestic rabbits in China, but the involved Chlamydia species was not determined [16]. 
To address these questions, we aimed to (i) investigate the prevalence of C. caviae in guinea pigs in Switzerland and in The Netherlands as well as its zoonotic potential, (ii) determine chlamydial occurrence in rabbits with or without contact to guinea pigs, (iii) perform ompA genotyping of C. caviae-positive samples to assess any strain diversity and (iv) determine further genetic markers for genotyping based on genomic comparisons between the reference strain GPIC, the Dutch zoonotic strain NL_Conj_Li and the German strain 04DC41.

\section{Results}

2.1. Chlamydiaceae and C. caviae Prevalence Data

Details of the Chlamydiaceae-positive husbandries in the Swiss and Dutch study are shown in Table 1.

The overall percentage of positive Swiss samples for Chlamydiaceae was $2.3 \%(18 / 784$ samples) with a mean $\mathrm{Ct}$ value of 32.8 . Of these, a total of $2.7 \%(15 / 553)$ positive swabs were collected from 14 guinea pigs across six husbandries and a total of $1.3 \%(3 / 231)$ positive swabs were collected from three rabbits originating from three different husbandries. Of the sampled husbandries, three were hosting only guinea pigs, one only rabbits and the remaining five hosting both animal species in the same enclosures. The 18 positive samples were identified in $1.1 \%(4 / 370)$ of the rectal, $2.6 \%(2 / 77)$ of the individual conjunctival and $3.5 \%(12 / 337)$ of the pooled conjunctival swabs (Table 2$)$. Eight samples originating from seven Chlamydiaceae-positive guinea pigs across two different husbandries could be further identified as C. caviae, resulting in a total Swiss C. caviae positivity of $2.7 \%$ (7/260 guinea pigs). From one guinea pig (G55), a paired C. caviae-positive conjunctival and rectal swab was available. In six Chlamydiaceae-positive samples (G65C, G67C, G68C, G191R, G238C and R103C), the chlamydial species could not be further identified. A complete list of all Swiss swabs collected and their results are presented in Supplementary Table S1.

The overall proportion of Dutch samples positive for Chlamydiaceae was $12.5 \%$ (25/200 samples), with a mean Ct value of 28.2 (Table 2). The 25 samples originated from $12 \%$ of the guinea pig population (105/878) belonging to five breeders $(13.5 \%)$. A sample was a composite swab from a range of two to six animals. Twenty-one of the 25 Chlamydiaceaepositive swabs tested positive in the VD4 C. caviae ompA PCR, of which eleven could be confirmed as $C$. caviae with subsequent sequencing. The eleven C. caviae-positive swabs originated from 5.7\% (50/878) of the sampled guinea pigs, found among three breeders. As certain samples could not be successfully sequenced, all 25 Chlamydiaceae-positive samples were analyzed by means of the C. caviae complete ompA gene PCR, resulting in an additional eight samples sharing $100 \%$ nucleotide identity with Chlamydia caviae clone Conj_Li ompA (GenBank accession number: KY777661). Altogether, in 19/200 of the Dutch samples C. caviae was identified, originating from $8.9 \%(78 / 878)$ of all sampled guinea pigs, found among $8.1 \%$ (3/37) of breeders. Due to the limited amount of DNA and low chlamydial load (high Ct values), the remaining six Chlamydiaceae-positive samples (sample number 62,67, 98, 138, 189 and 191) could not be further classified. A complete list of all Dutch swabs collected and their results are presented in Supplementary Table S2. 
Table 1. Details on the Chlamydiaceae-positive husbandries in the Swiss and Dutch prevalence study.

\begin{tabular}{|c|c|c|c|c|c|c|c|}
\hline \multicolumn{8}{|c|}{ Swiss Prevalence Study } \\
\hline $\begin{array}{l}\text { Husbandry } \\
\text { Number }\end{array}$ & $\begin{array}{l}\text { Type of } \\
\text { Husbandry }\end{array}$ & $\begin{array}{l}\text { Number of } \\
\text { Animals }\end{array}$ & $\begin{array}{l}\text { Clinical Signs } \\
\text { Present (y/n) }\end{array}$ & Type of Clinical Signs in Guinea Pigs and Rabbits & $\begin{array}{l}\text { Chlamydiaceae-Positive } \\
\text { Swabs (n)/ Total (n) }\end{array}$ & $\begin{array}{l}\text { Range of } \mathrm{Ct} \\
\text { Values }\end{array}$ & $\begin{array}{l}\text { C. caviae Confirmed (n)/ } \\
\text { Chlamydiaceae-Positive (n) }\end{array}$ \\
\hline 5 & Breeder & 22 & yes & $\begin{array}{l}\text { Subconjunctival fat deposition, serous and mucous ocular } \\
\text { discharge, lens opacification, chemosis, crust } \\
\text { accumulation }\end{array}$ & $6 / 76$ & $25.8-35.6$ & $3 / 6^{\mathrm{A}}$ \\
\hline 8 & Breeder & 11 & yes & Crust accumulation, serous ocular and nasal discharge & $5 / 23$ & $24-34.1$ & $5 / 5$ \\
\hline 18 & Private owner & 7 & yes & Crust accumulation & $1 / 15$ & 34.7 & $0 / 1^{\mathrm{B}}$ \\
\hline 19 & Private owner & 27 & yes & Hyperemia, crust accumulation & $1 / 55$ & 32 & $0 / 1^{\mathrm{B}}$ \\
\hline 21 & Private owner & 11 & yes & Mucous ocular discharge, serous nasal discharge & $1 / 24$ & 36.7 & $0 / 1$ \\
\hline 26 & Private owner & 12 & yes & $\begin{array}{c}\text { Serous nasal discharge, mucous ocular discharge, } \\
\text { hyperemia, crusts accumulation }\end{array}$ & $1 / 26$ & 32.3 & $0 / 1^{B}$ \\
\hline 28 & Private owner & 12 & yes & $\begin{array}{l}\text { Serous ocular discharge, corneal opacification, } \\
\text { subconjunctival fat deposition }\end{array}$ & $1 / 25$ & 34.6 & $0 / 1$ \\
\hline 57 & Private owner & 1 & no & - & $1 / 2$ & 37.6 & $0 / 1$ \\
\hline \multicolumn{8}{|c|}{ Dutch Prevalence Study } \\
\hline $\begin{array}{l}\text { Husbandry } \\
\text { Number }\end{array}$ & $\begin{array}{c}\text { Type of } \\
\text { Husbandry }\end{array}$ & $\begin{array}{l}\text { Number of } \\
\text { Animals }\end{array}$ & $\begin{array}{l}\text { Clinical Signs } \\
\text { Present (y/n) }\end{array}$ & Type of Clinical Signs in Guinea Pigs & $\begin{array}{l}\text { Chlamydiaceae-Positive } \\
\text { Swabs (n)/ Total (n) }\end{array}$ & $\begin{array}{l}\text { Range of } \mathrm{Ct} \\
\text { Values }\end{array}$ & $\begin{array}{l}\text { C. caviae Confirmed (n)/ } \\
\text { Chlamydiaceae-Positive (n) }\end{array}$ \\
\hline 13 & Show breeder & 83 & yes & $\begin{array}{l}\text { conjunctivitis, corneal edema, corneal lesions, rhonchi, } \\
\text { painful mandibular lymph nodes }\end{array}$ & $9 / 20$ & $24.6-36.3$ & $7 / 9$ \\
\hline 19 & Show breeder & 31 & no & - & $1 / 7$ & 37.7 & $0 / 1$ \\
\hline 28 & Show breeder & 8 & no & - & $1 / 2$ & 37.2 & $0 / 1$ \\
\hline 38 & Trader & 51 & yes & $\begin{array}{l}\text { Conjunctivitis, mucous and mucopurulent ocular } \\
\text { discharge, blepharospasm, mucous nasal discharge, nasal } \\
\text { stridor, enlarged mandibular lymph nodes }\end{array}$ & $13 / 13$ & $22-36.1$ & $11 / 13$ \\
\hline
\end{tabular}

${ }^{\mathrm{A}}$ Insufficient DNA for C. caviae typing; ${ }^{\mathrm{B}}$ C. psittaci positive samples. 
Table 2. Details on the Chlamydiaceae-, C. caviae-, and C. psittaci- positive samples of the Swiss and Dutch prevalence study.

\begin{tabular}{|c|c|c|c|c|c|c|c|c|c|}
\hline & \multicolumn{5}{|c|}{ Switzerland } & \multicolumn{4}{|c|}{ The Netherlands } \\
\hline & $\begin{array}{l}\text { Chlamydiaceae- } \\
\text { Positive }^{\mathrm{A}} \\
\text { (Guinea } \\
\text { Pigs/Rabbits) }\end{array}$ & $\begin{array}{c}\text { C. caviae-Positive } \\
\text { (Guinea } \\
\text { Pigs/Rabbits) }\end{array}$ & $\begin{array}{c}\text { C. psittaci-Positive } \mathrm{C}^{\mathrm{C}} \\
\text { (Guinea } \\
\text { Pigs/Rabbits) }\end{array}$ & $\begin{array}{l}\text { Chlamydiaceae- } \\
\text { Negative } \\
\text { (Guinea } \\
\text { Pigs/Rabbits) }\end{array}$ & $\begin{array}{c}\text { Total of Collected } \\
\text { Samples } \\
\text { (Guinea } \\
\text { Pigs/Rabbits) } \\
\end{array}$ & $\begin{array}{l}\text { Chlamydiaceae- } \\
\text { Positive }^{\mathrm{A}}\end{array}$ & $\begin{array}{l}\text { C. caviae- } \\
\text { Positive }^{B}\end{array}$ & $\begin{array}{l}\text { Chlamydiaceae- } \\
\text { Negative }\end{array}$ & $\begin{array}{c}\text { Total of } \\
\text { Collected } \\
\text { Samples }\end{array}$ \\
\hline $\begin{array}{l}\text { Conjunctival } \\
\text { samples }\end{array}$ & $11 / 3$ & $7 / 0$ & $0 / 2$ & $282 / 118$ & 293/121 & 25 & 19 & 175 & 200 \\
\hline $\begin{array}{l}\text { Individual } \\
\text { samples }\end{array}$ & $1 / 1$ & $1 / 0$ & $0 / 1$ & $65 / 10$ & $66 / 11$ & 0 & 0 & 0 & 0 \\
\hline $\begin{array}{c}\text { Composite } \\
\text { samples }\end{array}$ & $0 / 0$ & $0 / 0$ & $0 / 0$ & $0 / 0$ & $0 / 0$ & 25 & 19 & 175 & 200 \\
\hline $\begin{array}{c}\text { Rectal } \\
\text { samples }\end{array}$ & $4 / 0$ & $1 / 0$ & $2 / 0$ & $256 / 110$ & $260 / 110$ & 0 & 0 & 0 & 0 \\
\hline Total & $15 / 3$ & $8 / 0$ & $2 / 2$ & $538 / 228$ & $553 / 231$ & 25 & 19 & 175 & 200 \\
\hline
\end{tabular}

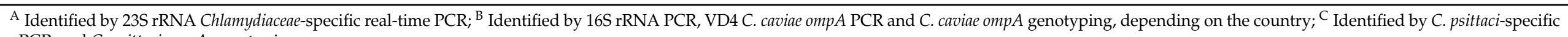
qPCR und C. psittaci ompA genotyping. 


\subsection{Molecular Typing of C. caviae from the Swiss and Dutch Samples}

Of the positive samples $(n=64)$ amplified and sequenced, complete sequences for the ompA gene were successfully obtained from 33 samples, exclusively from guinea pigs. The Swiss samples of this study ( $\mathrm{n}=5$, Supplementary Table S1) revealed $100 \%$ nucleotide identity with Chlamydia caviae clone NL_Conj_Li ompA gene (GenBank accession number: KY777661). The remaining 28 Dutch $(\mathrm{n}=13$, Supplementary Table S2) and previous Swiss samples $(n=15,[6])$ had $100 \%$ nucleotide identity with the $C$. caviae strain isolated from the bronchoalveolar fluid of one of the patients in the Dutch zoonotic case [8] and its cultured clone (GenBank accession number: KY777661 and KY777669, respectively). All samples had a lower nucleotide identity $(98.8 \%$ ) with the C. caviae GPIC reference strain (GenBank accession number: AE015925.1). A phylogenetic tree based on the ompA sequences of different $C$. caviae-positive samples per country is displayed in Figure $1[1,13,17]$. Sequences were compared to the reference strain GPIC, the previously reported C. caviae 06G282 from a horse in Germany (GenBank accession number: GQ332575) and ompA from C. psittaci 6BC (GenBank accession number: CP002586.1) as an outgroup. While differences could be detected between GPIC and 06G282, ompA was identical in all other isolates reported here.

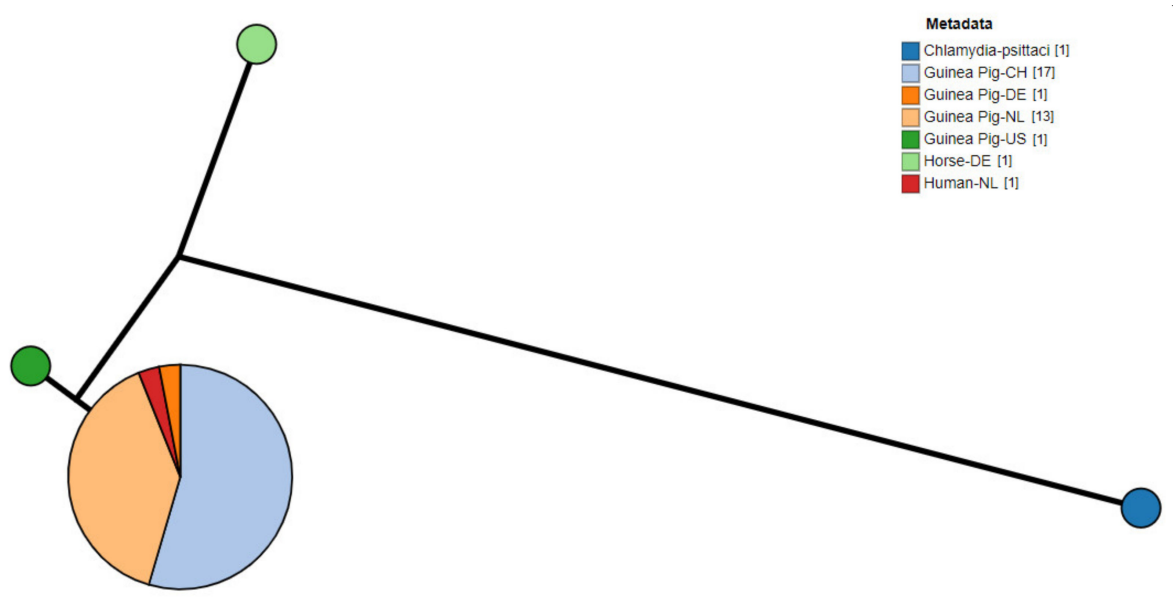

Figure 1. Phylogram of C. caviae ompA sequences from diverse sources. Metadata label shows the host and country of origin. C. psittaci was used as outgroup. (CH: Switzerland; NL: The Netherlands; DE: Germany; US: United States of America).

\subsection{Whole Genome Sequencing of C. caviae Isolates}

As expected, the hybrid assembly of NL_Conj_Li resulted into one chromosomal contig and one plasmid contig and the chromosomal sequence of 04DC41 was present in nine contigs while the plasmid was present in one contig. The size of the chromosomes and plasmids is approximately $1.17 \mathrm{Mb}$ and $7.5 \mathrm{~kb}$, respectively, with $39 \% \mathrm{GC}$ content and just under 1000 putative CDS, very similar to the previously published complete genome GPIC genome (Table 3). The average nucleotide identity of the complete isolates is $>99 \%$.

Table 3. Properties of the genomic sequences of the two C. caviae isolates.

\begin{tabular}{ccccc}
\hline & NL_Conj_Li Chromosome & NL_Conj_Li Plasmid & 04DC41 Chromosome & 04DC41 Plasmid \\
\hline Size & $1,175,666$ & 7532 & $1,175,594$ & 7659 \\
Contigs & 1 & 1 & 9 & 1 \\
GC\% & 39.27 & 33.48 & 39.26 & 33.32 \\
CDS & 987 & 8 & 988 & 8 \\
rRNA & 3 & & 3 & 38 \\
tRNA & 38 & 99.79 & 99.54 & 99.84 \\
ANI to GPIC & 99.55 & & \\
\hline
\end{tabular}

Comparison of the complete genomes and plasmids using BLAST ring image generator (BRIG) underline the high degree of similarity between the genomes (Figure 2). The recently 
well characterized genes $\sin C$ and inc $A$ were compared between the three genomes as well as other putative divergent targets. While $\sin C$ and inc $A$ are $100 \%$ identical between NL_Conj_Li and 04DC41, the genes have $99.87 \%$ and $99.63 \%$ sequence identity respectively, compared to GPIC (Supplementary Table S3). One region is specifically divergent between NL_Conj_Li and 04DC41 compared to GPIC (Figures 2 and 3). The region is 100\% identical between NL_Conj_Li and 04DC41 and contains four predicted coding sequences. The region in GPIC encodes seven predicted coding sequences but no function can be predicted for any of the genes. No suitable genetic markers could be identified that would sufficiently discriminate between NL_Conj_Li and 04DC41 as target for further molecular screening.
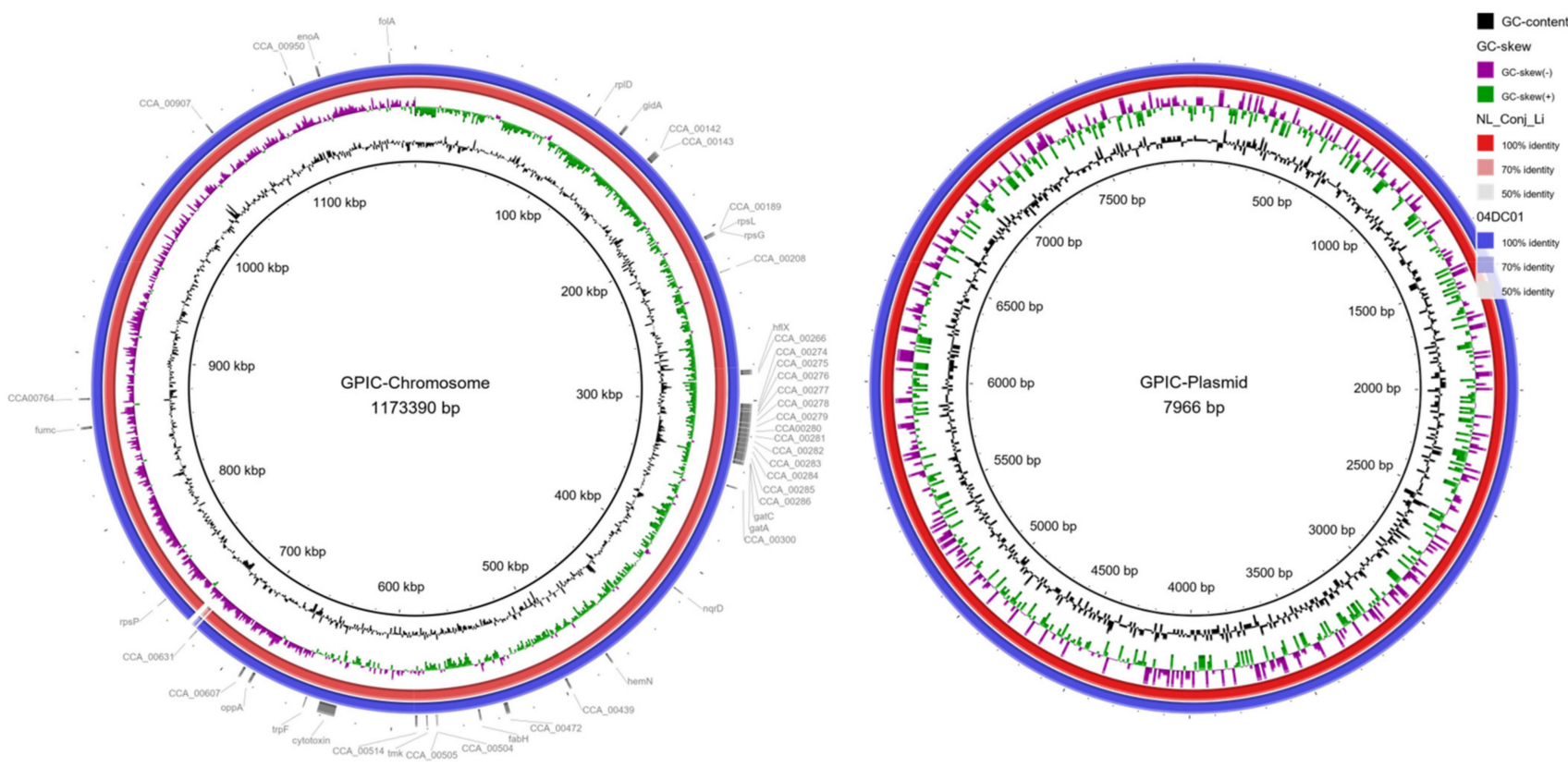

Figure 2. BRIG comparison of C. caviae genomes NL_Conj_Li and 04DC01 to reference strain GPIC. The left panel shows the comparison of the chromosome, the right panel is the comparison of the plasmid. From inside to outside, the rings represent the GC content, the GC skew and the percentage sequence identity to the reference genome. Putative gene targets that were compared for discrimination between NL_Conj_Li and 04DC01 are indicated in the outermost ring. One region is specifically divergent between NL_Conj_Li and 04DC01 compared to GPIC (see Figure 3, 710 kbp).

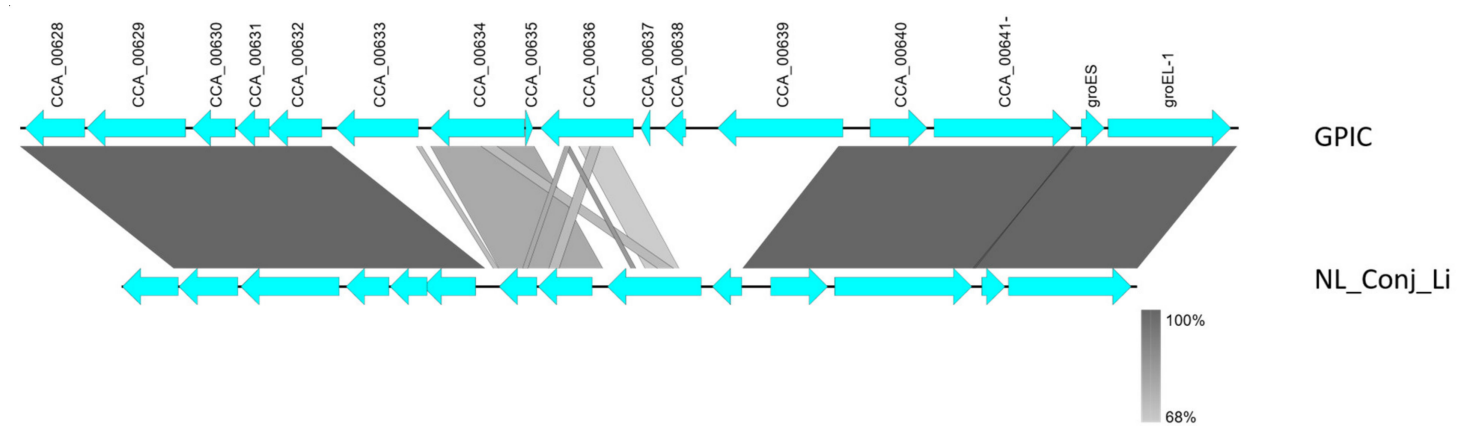

Figure 3. Detailed view of the genomic region divergent between NL_Conj_Li and 04DC01 compared to GPIC (see Figure 2). At close examination of this region, seven hypothetical genes in the GPIC chromosome are absent in NL_Conj_Li and 04DC01 and the region contains four predicted coding sequences. The function of these predicted genes is unknown, and the region is $100 \%$ identical between NL_Conj_Li and 04DC01.

\subsection{Other Chlamydial Species in Guinea Pigs and Rabbits}

In the Swiss samples, C. psittaci was detected in four samples from two guinea pigs and two rabbits (G161R, G184R, R59C_left and R68C) in the C. psittaci specific real-time PCR. 
Subsequent amplification and sequencing led to three samples (G161R, R59C_left and R68C) sharing at least 99.4\% nucleotide identity with C. psittaci strain 6BC and 84/55 (GenBank accession number: NR_036864.2 and CP003790.1, respectively). Additional C. psittacispecific ompA genotyping (1050 base pairs) of the four positive samples led to one additional C. psittaci isolate 84/55 (GenBank accession number: CP003790.1), originating from a guinea pig rectal sample (G184R). All C. psittaci confirmed samples shared the highest ompA similarity (97.3-99.6\% nucleotide identity) with C. psittaci strain 84/55 (GenBank accession number CP003790.1), which had been isolated from a budgerigar and belongs to the C. psittaci genotype A [18]. C. psittaci ompA genotyping was unsuccessful in one sample (R59C_left). The four positive samples originated from four different husbandries, which kept both animal species in the same enclosures. None of the positive husbandries contained more than one Chlamydia species at the same time.

Three months after the first sampling, a second sampling of three C. psittaci-positive animals (two guinea pigs and one rabbit) ensued in negative results for all seven swabs (four conjunctival and three rectal swabs) by means of the 23S rRNA Chlamydiaceae-specific real-time PCR screening method (data not shown).

\subsection{Clinical Signs in Chlamydiaceae-Positive Guinea Pigs and Rabbits}

Clinical examination of all Swiss animals revealed a total of 24.9\% (92/360) exhibiting either nasal discharge, ocular discharge or other ocular pathologies, all possible clinical signs related to a chlamydial infection. In detail, nasal discharge (serous, mucous, hemorrhagic or mucopurulent) was seen in $2.3 \%(6 / 260)$ and $15.5 \%(17 / 110)$ of the guinea pigs and rabbits, respectively. Furthermore, ocular discharge (serous, seromucous or mucopurulent) was noted in 7.7\% (20/260) and 13.6\% (15/110) of the guinea pigs and rabbits, respectively. Other ocular pathologies (i.e., lens opacification, subconjunctival deposition of fat, corneal lesions, accumulation of crusts and blindness) as well as typical Chlamydia-induced conjunctivitis signs (hyperemia, chemosis and inflammation of the conjunctiva) were reported in $21 \%(55 / 260)$ and $10.9 \%(12 / 110)$ of the guinea pigs and rabbits, respectively. Data from four deceased rabbits (4/35) was not available. Among the above-mentioned symptomatic animals, 4.4\% (4/92) were positive for $C$. caviae, exhibiting either crusts bilaterally, subconjunctival fat deposition, serous ocular discharge or bilateral lens opacification, whereas $2.2 \%$ (2/92) were positive for C. psittaci, exhibiting an accumulation of crusts around the eyes, one also displaying mucous nasal discharge. Among the asymptomatic animals, $1.8 \%$ (5/278) displayed a positive C. caviae or C. psittaci result. C. caviae- or C. psittaci-positive symptomatic animals were found in $6.3 \%(4 / 64)$ of the sampled husbandries.

Clinical examination of all Dutch guinea pigs revealed a total of 3.4\% (30/878) with clinical signs indicative for a chlamydial infection, distributed over 16 composite swabs. Ocular discharge (serous, seromucous, mucous or mucopurulent) was present in $56.7 \%$ $(17 / 30)$ of the diseased guinea pigs, whereas nasal discharge (serous, mucous or purulent) was only observed in $20 \%(6 / 30)$ of the diseased guinea pigs. Ocular pathologies (i.e., corneal lesions, hypopyon, corneal vascularization) as well as typical Chlamydia-related conjunctivitis signs were recorded in $43.3 \%$ (13/30) of the diseased guinea pigs. Additionally, 10\% (3/30) of the diseased guinea pigs showed respiratory sounds (i.e., rhonchi and stridor) during lung auscultation. Among the above-mentioned symptomatic animals, 20\% $(6 / 30)$ were positive for C. caviae, exhibiting either mucous or mucopurulent ocular discharge $(5 / 6)$ or mucous nasal discharge (3/6). All six symptomatic animals were diagnosed C. caviae-positive by one composite swab and originated from one single Dutch breeder.

\subsection{Symptoms Reported by Guinea Pig and Rabbit Owners}

Reports from Swiss owners $(n=30)$ revealed that two owners of the six abovementioned positive husbandries for $C$. caviae $(n=2)$ or $C$. psittaci $(n=4)$ suffered from respiratory symptoms in the previous year, specifically asthma and recurrent common colds, respectively. In addition, the latter mentioned owning cats with outdoor access 
which had a positive confirmed Chlamydiaceae result (Chlamydia felis) in the months prior. Reports from owners $(n=34)$ of the deceased rabbits were not available.

Reports from the Dutch breeders $(n=37)$ revealed that none of the owners of the C. caviae positive husbandries $(n=3)$ suffered of any respiratory signs or pneumonia in the last five years.

\section{Discussion}

\subsection{Prevalence Study in Swiss and Dutch Guinea Pigs}

The present study detected an overall C. caviae prevalence of $2.7 \%(7 / 260)$ and $8.9 \%$ $(78 / 878)$ in guinea pigs and of 6.6\% (2/30) and 8.1\% (3/37) husbandries in Switzerland and in The Netherlands, respectively. Both prevalence rates are considerably lower than the only available $C$. caviae occurrence data of $48 \%$ (59/123) previously reported in Switzerland [6]. In contrast to our study, Lutz-Wohlgroth et al. sampled predominantly ill guinea pigs that presented to the veterinary hospital in Zurich, with either clinical signs of ocular, genital or respiratory disease or a reduced general condition [6]. Half of the animals in the latter study originated from one breeder who kept the guinea pigs under suboptimal housing and hygiene conditions. We could speculate that the $C$. caviae prevalence reported at that time was high due to a chlamydiosis outbreak in the latter husbandry, and therefore was not representative of general C. caviae prevalence in Switzerland. In our study, randomly selected husbandries were sampled, with none of them reporting any major health issues in their animals, therefore the sample ought to better represent the C. caviae prevalence in the general guinea pig population.

In general, the prevalence at husbandry level in our study was low, but the prevalence within husbandries differed. This could be due to differences in husbandries (i.e., number of animals per $\mathrm{m}^{2}$, feeding and living conditions) and animal welfare. More than half of the C. caviae-positive samples (11/19) were detected in the husbandry of one Dutch trader (a business receiving different animal species and distributing them to pet shops/private owners), which may indicate that $C$. caviae can spread fast within one husbandry, as was also observed in the similar chlamydiosis outbreak in the Lutz-Wohlgroth et al. study [6]. Furthermore, the overall prevalence appeared to be lower in the Swiss study, which might be the result of smaller husbandries, the largest owning 50 guinea pigs (with a mean of 12 guinea pigs per husbandry), while the sampled Dutch husbandries kept up to 300 guinea pigs (with a mean of 39 guinea pigs per husbandry). It has been mathematically proven that a higher animal density and a direct mode of pathogen transmission can lead to increased pathogen spread $[17,19]$. However, the data between the Dutch and Swiss study cannot be easily compared due to the variation in husbandry types and the different sampling strategies used (composite swabs versus individual swabs).

\subsection{Prevalence Study in Swiss Pet Rabbits}

We did not detect $C$. caviae in rabbits with close contact to guinea pigs or in deceased rabbits, although C. caviae was previously detected in the conjunctival swab of a rabbit and a cat living in the same husbandry as a C. caviae-infected guinea pig flock [6]. The C. caviae-positive rabbit in the latter study displayed mild serous ocular discharge [6]. $\mathrm{Ni}$ et al. reported a Chlamydia seroprevalence of $17.9 \%(143 / 800)$ in pet rabbits in China, without determining which Chlamydia species was involved or if any clinical signs could be observed [16]. In our study, the Chlamydia occurrence in pet rabbits was $1.8 \%(2 / 110)$ and only C. psittaci genotype A was identified, but serology was not performed, making direct comparisons between studies difficult.

\subsection{C. caviae Sequencing}

In our study, all ompA gene sequences retrieved from Dutch and Swiss samples and the previous Swiss study [6] shared 100\% nucleotide identity with the strains KY777661 and KY777669, isolated by Ramakers et al. [8]. Genotyping of the ompA gene is frequently used in Chlamydia, although resolution is limited and evolution might be divergent from other 
parts of the genome [20-22]. However, further characterization of C. caviae NL_Conj_Li and 04DC41 did not reveal any suitable genetic markers that would sufficiently discriminate both strains, while they were isolated at different timepoints (2014 versus 2004) and at different locations (Netherlands versus Germany). These results might indicate, that one C. caviae strain is currently circulating in European guinea pigs, which is different from the reference strain GPIC.

Comparisons of previously described regions of variability and potential virulence factors including the MLST genes, inc A, $\sin C, \operatorname{omp} A$, the cytotoxin polymorphic outer membrane proteins, as well as the plasmid revealed differences with the reference genome GPIC but only a small number of SNPs between the sequenced isolates NL_Conj_Li and 04DC41. Further epidemiological studies on a global scale, including the typing of C. caviae omp $A$ gene in other countries, are necessary to explore the $C$. caviae strain diversity worldwide. Such studies would require isolation and culturing of the pathogen to ensure that a single pathogen is sequenced, and that enough DNA can be isolated, which is specifically challenging for Oxford Nanopore sequencing due to the high amount of input DNA.

\subsection{Clinical Signs in Chlamydia-Positive Animals}

Typical clinical signs for a chlamydial infection in guinea pigs (i.e., conjunctivitis, ocular and nasal discharge, pneumonia, abortions and vaginal discharge) were present in $81.4 \%(48 / 59)$ of the C. caviae-positive animals of the previous Swiss study [6], whereas we only observed $11.8 \%(10 / 85)$ C. caviae-positive guinea pigs suffering from any clinical signs. As the majority of the infected animals in our study were asymptomatic, a persistent infection within a herd might go unnoticed, unless all animals (including asymptomatic ones) are tested. All positive symptomatic and asymptomatic animals should be treated with antibiotics (tetracycline) in order to reduce the spreading of the pathogen and therefore also lowering the zoonotic risk to the owners. In our field study setting, no complete ophthalmologic examination was conducted and additional typical clinical signs such as abortions as well as vaginal discharge were not included in our questionnaires (considering possible recall biases from the owners and lack of records for disease history in their animals). Therefore, it cannot be completely ruled out that more $C$. caviae-positive guinea pigs exhibited ocular or genital tract infection signs. However, a correlation between ocular clinical signs and C. caviae positivity was not observed in this study.

\subsection{C. psittaci in Guinea Pigs and Rabbits-A New Zoonotic Risk?}

Current veterinary advice recommends separation of guinea pigs from rabbits in order to minimize the potential pathogen transmission between these two species [11]. Pathogens such as Bordetella bronchiseptica and dermatophytes (i.e., Trichophyton mentagrophytes and T. benhamiae) are capable of infecting either species [11,23]. In our study, none of the husbandries had positive C. caviae or C. psittaci results in both animal species simultaneously. However, due to the intermittent shedding of Chlamydia, it might be possible that additional positive animals remained unnoticed.

Despite its broad host range, C. psittaci predominantly causes chlamydiosis in different avian species. Clinical signs range from asymptomatic to nasal and ocular discharge, air sacculitis, pneumonia, enteritis, hepatitis and chronic infections, the latter leading to intermittent shedding of the bacterium [24]. Avian chlamydiosis caused by C. psittaci is a notifiable disease in many countries (including The Netherlands and Switzerland). Reports on C. psittaci in cats, dogs, experimentally infected cattle and horses reflect its ability to induce ocular and respiratory signs as well as reproductive losses in other animal species [25-28]. Nonetheless, cases of clinical diseases in non-avian hosts are generally an exempt [29].

The only study on C. psittaci infections in domestic rabbits dates back to 1974, when substantial lethality and ocular pathologies (i.e., anterior uveitis and conjunctivitis) were reported in experimental infections [14]. However, these lagomorphs were infected with 
high doses of the C. psittaci M56 strain (isolated from muskrats and snowshoe hares during a die-off event some years previously [12]), while all positive animals in our study harbored the C. psittaci genotype A. Previously, the C. psittaci strain C6/98, belonging to genotype A (GenBank accession number: NZ_KE359921-NZ_KE360062) (data unpublished) had been isolated from a conjunctival swab of a domestic rabbit from Germany in 1998 (personal communication, K. Sachse). In our study, the two C. psittaci-positive guinea pigs showed no clinical signs, whereas the two positive rabbits had crusts around their eyes, one of them also displaying mucous nasal discharge but no conjunctivitis. At this point, the role of C. psittaci as a pathogen as well as the shedding frequency and duration of the agent in both animal species remain unresolved. Further investigations are thus needed to determine the prevalence, pathogenesis and presence of clinical signs in these animal species. Isolation and culture of C. psittaci strains from guinea pigs and/or rabbits will clarify their viability and infectivity and will help assess their potential danger for human transmission.

Due to the unexpected detection of the zoonotic chlamydial species C. psittaci in guinea pigs and rabbits in Switzerland as well as the high motivation of the corresponding owners for follow-up testing, a second sampling of the two positive guinea pigs and of one of the two rabbits was performed. All three animals were negative in the conjunctival and rectal swab samples by the $23 \mathrm{~S}$ Chlamydiaceae screening method (data not shown). This could be attributed to (i) possible contamination of the conjunctivae and/or gastrointestinal tract at the time of the first sampling; (ii) potential chlamydial intermittent shedding with no detection at the second sampling; (iii) elimination of the agent by the host immune system or (iv) suboptimal sampling procedure performed by the owners with insufficient pressure applied, causing the flocked swabs to miss the infected cells. Still, further investigations of the Chlamydia-positive husbandries would be of interest to clarify the veterinary and potential public health concern arising from such C. psittaci infections.

\subsection{Zoonotic Potential of C. caviae and C. psittaci}

Except one individual suffering from asthma, owners of $C$. caviae-positive animals in our study did not report any respiratory discomfort in the years prior. None of the owners in Switzerland reported any signs of conjunctivitis. Therefore, our study did not provide further insight into the zoonotic potential of $C$. caviae as previously recognized $[6,8,9]$. Furthermore, we could not prove any zoonotic risks related to the presence of C. psittaci in guinea pigs and rabbits. In our study, one owner of a C. psittaci-positive guinea pig suffered from recurrent common colds, but due to ethical regulations, we were not allowed to take samples from the owners. Non-avian C. psittaci strains are considered to have a lower zoonotic potential, since most of the reported human psittacosis cases could be traced back to contact with avian species [29,30]. Additionally, C. psittaci strains isolated directly from mammals displayed significantly reduced infectivity and organ dissemination in an in vivo chicken embryo model when compared to the $C$. psittaci strains isolated directly from avian species [31]. However, in 2014, a cluster of psittacosis cases was reported in Australia when five veterinary students and university staff members suffered from fever, fatigue and pneumonia after contact with the infected fetal membranes of a mare with placentitis [32]. The abnormal fetal membranes were found to harbor the $C$. psittaci isolate $6 \mathrm{BC}$ belonging to the genotype A [33].

Although the present data and the absence of severe clinical signs in the guinea pigs, rabbits and owners do not warrant urgent and large-scale surveys in humans, either in Switzerland or in The Netherlands, the zoonotic potential of both chlamydial species should not be underestimated. It is therefore recommended to further characterize and type positive Chlamydiaceae results in symptomatic animals in order to confirm the presence or absence of possible zoonotic strains. In addition, we recommend that vulnerable populations such as children, immunosuppressed adults/owners and personnel in the veterinary field be informed about the zoonotic risks and remain cautious, particularly when animals present typical Chlamydia-related clinical signs. 


\section{Materials and Methods}

\subsection{Sampling of Swiss Guinea Pigs and Rabbits and Swab Preparation}

Between August 2019 and March 2021, a total of 784 swabs were collected from 370 pet guinea pigs and rabbits from different geographical locations in Switzerland. In total, 260 guinea pigs from 29 different husbandries and 75 rabbits from 22 husbandries in 12 different Swiss cantons were sampled, some of these husbandries $(n=30)$ keeping both species in the same enclosure. Additionally, 35 deceased pet rabbits which were investigated by the National Reference Center for Poultry and Rabbit Diseases (NRGK) for cause of death were added to the sample set. These 35 additional rabbits originated from 34 different husbandries in 11 different Swiss cantons. Husbandries $(n=64)$ included breeders $(n=6)$, zoos and community centers $(n=2)$, pet shops $(n=2)$ and private owners $(n=54)$. The sample set included a pooled conjunctival swab $(n=337)$ and a rectal swab $(n=370)$ from each animal. If the animal showed any signs of an ocular disease (i.e., ocular discharge or ocular pathologies), conjunctival swabs from both eyes were taken individually $(\mathrm{n}=77)$, leading to a total number of 784 swabs (Table 4$)$. Dry small-scale flocked swabs (FLOQSwabs Copan Flock Technologies, Brescia, Italy) were used for sampling and stored at $-20^{\circ} \mathrm{C}$ until DNA extraction. Additionally, age, sex, breed, health status, clinical signs, living conditions and geographic origin of the animals, as well as health status and clinical signs of the owners were noted. The study was conducted in strict compliance with the Animal Welfare Act of Switzerland. It was approved by the Cantonal Veterinary Office of Zurich (approval number ZH129/2019, 31548).

For the DNA extraction of the Swiss swab samples, a commercially available kit (Maxwell®16 DNA Purification, Buccal Swab/LEV, \#AS1295, Promega, Fitchburg, WI, USA) was used according to the manufacturer's instructions. Using the Maxwell ${ }^{16} 6$ machine (Promega AG, Dübendorf, Switzerland) for the DNA extraction, a final elution volume of $50 \mu \mathrm{L}$ was obtained.

\subsection{Sampling of Dutch Guinea Pigs and Swab Preparation}

Between October and November 2019, a total of 878 guinea pigs from 37 different breeders were sampled in eight different provinces in The Netherlands and one in Belgium (Table 4). The 37 husbandries included show breeders $(n=20)$, non-show breeders $(n=12)$ and petting farms $(n=5)$. Per husbandry, multiple composite swab samples were taken (Aluminum swab (sterile), Medical direct, The Netherlands), one composite swab including the sampling of one to six guinea pigs. This resulted in 200 composite swab samples, originating either from asymptomatic $(n=184)$ or symptomatic $(n=16)$ guinea pigs (Supplementary Table S2). One single-sided conjunctival sample was collected per guinea pig. Swabs were stored at $-20^{\circ} \mathrm{C}$ until DNA extraction. All guinea pigs were assessed for their overall health status prior to sample collection, with a brief clinical examination of the respiratory system, including the nose and eyes. Additionally, age and sex of the symptomatic guinea pigs, size and disinfection methods of the enclosures as well as health status and clinical signs of the owners were noted. The study was conducted in strict compliance with the Animal Act 2011 in The Netherlands. In accordance with the national regulations on animal experimentation, no ethical approval for the sampling was needed.

DNA extraction was performed with a NucliSENS easyMAG (Biomerieux, Zaltbommel, The Netherlands). Swabs were suspended in $1.5 \mathrm{~mL}$ Tryptose Phosphate $2.95 \% \mathrm{w} / \mathrm{v}$ with $52 \mathrm{mg} / \mathrm{L}$ gentamicin (BM 330, WBVR, Lelystad, The Netherlands) and thoroughly vortexed. From this suspension, $500 \mu \mathrm{L}$ was added to $2 \mathrm{~mL}$ NucliSENS lysis buffer for off-board lysis. After at least one hour of incubation at room temperature, the lysis buffer was added to $80 \mu \mathrm{L}$ of silica and extracted according to the manufacturer's instructions for specific protocol B. Within this protocol, an optimized washing protocol was used with extra and longer washing steps. The final elution volume was $100 \mu \mathrm{L}$. 
Table 4. Number of animals and origin of samples by country.

\begin{tabular}{|c|c|c|c|c|c|c|c|c|c|c|c|c|c|c|}
\hline & \multicolumn{6}{|c|}{ Switzerland } & \multicolumn{6}{|c|}{ The Netherlands } & \multirow{3}{*}{$\begin{array}{c}\text { Total } \\
\text { Number of } \\
\text { Samples }\end{array}$} & \multirow{3}{*}{$\begin{array}{c}\text { Total } \\
\text { Number o } \\
\text { Animals }\end{array}$} \\
\hline & \multirow{2}{*}{ Husbandries } & \multirow{2}{*}{ Animals } & \multicolumn{3}{|c|}{ Conjunctival Samples } & \multirow{2}{*}{$\begin{array}{c}\text { Rectal } \\
\text { Samples }\end{array}$} & \multirow{2}{*}{ Husbandries } & \multirow{2}{*}{ Animals } & \multicolumn{3}{|c|}{ Conjunctival samples } & \multirow{2}{*}{$\begin{array}{c}\text { Rectal } \\
\text { Samples }\end{array}$} & & \\
\hline & & & Individual & Pooled & Composite & & & & Individual & Pooled & Composite $^{1}$ & & & \\
\hline $\begin{array}{l}\text { Guinea } \\
\text { Pigs }\end{array}$ & 30 & 260 & 66 & 227 & 0 & 260 & 37 & 878 & 0 & 0 & 200 & 0 & 753 & 1138 \\
\hline Rabbits & 34 & 110 & 11 & 110 & 0 & 110 & 0 & 0 & 0 & 0 & 0 & 0 & 231 & 110 \\
\hline Total & $64^{2}$ & 370 & & 414 & & 370 & 37 & 878 & & 200 & & 0 & 984 & 1248 \\
\hline
\end{tabular}

${ }^{1}$ Swabs from one conjunctiva with a range of one to six guinea pigs per composite swab; ${ }^{2}$ Certain husbandries had guinea pigs and rabbits living together in the same enclosure. 


\subsection{Chlamydiaceae Screening of Swiss and Dutch Samples}

All extracted samples $(n=984)$ were first screened using the $23 S$ rRNA Chlamydiaceaespecific real-time PCR, resulting in an amplicon of 111 base pairs and using primers Ch23S-F, Ch23S-R and probe Ch23S-p (Supplementary Table S4) [34]. Internal positive controls included enhanced green fluorescent protein (eGFP, [35]) for the Swiss samples and the ChMIX3IPC-template for the Dutch samples (Table 5). All Swiss samples were tested in duplicate. In each run, molecular grade water was used as negative control. For the Swiss samples, a sevenfold dilution of Chlamydia abortus DNA with a defined number of DNA copies was added in each run and used as positive control and standard curve. The threshold value for Chlamydiaceae was set at 0.1 and a sample was considered positive when both duplicates showed a mean cycle threshold (Ct value) $<38$. If the duplicates showed a higher $\mathrm{Ct}$ value or inhibited amplification, they were repeated in duplicate and in a tenfold dilution. Samples repeatedly showing a slightly higher value than 38 (i.e., $\mathrm{Ct}$ values of 40) were considered questionably positive and submitted for further typing.

For the Dutch samples, a dilution series of three Chlamydia psittaci DNA samples were used as positive control [36]. Dutch samples were submitted for further typing when $\mathrm{Ct}$ values were $<40$.

\subsection{Typing of Chlamydiaceae-Positive Samples}

Positive samples by the Chlamydiaceae screening PCR were further investigated according to the decision tree displayed in Figure 4. All primers and probes used in the further PCR tests are listed in Table 5. All Swiss primers and probes were purchased from Microsynth (Balgach, Switzerland). All Dutch primers and probes were purchased from Eurogentec, Life Technologies Europe, Genscript, Biolegio and Integrated DNA Technologies. All reaction mix concentrations and cycling protocols are summarized in Supplementary Table S4.

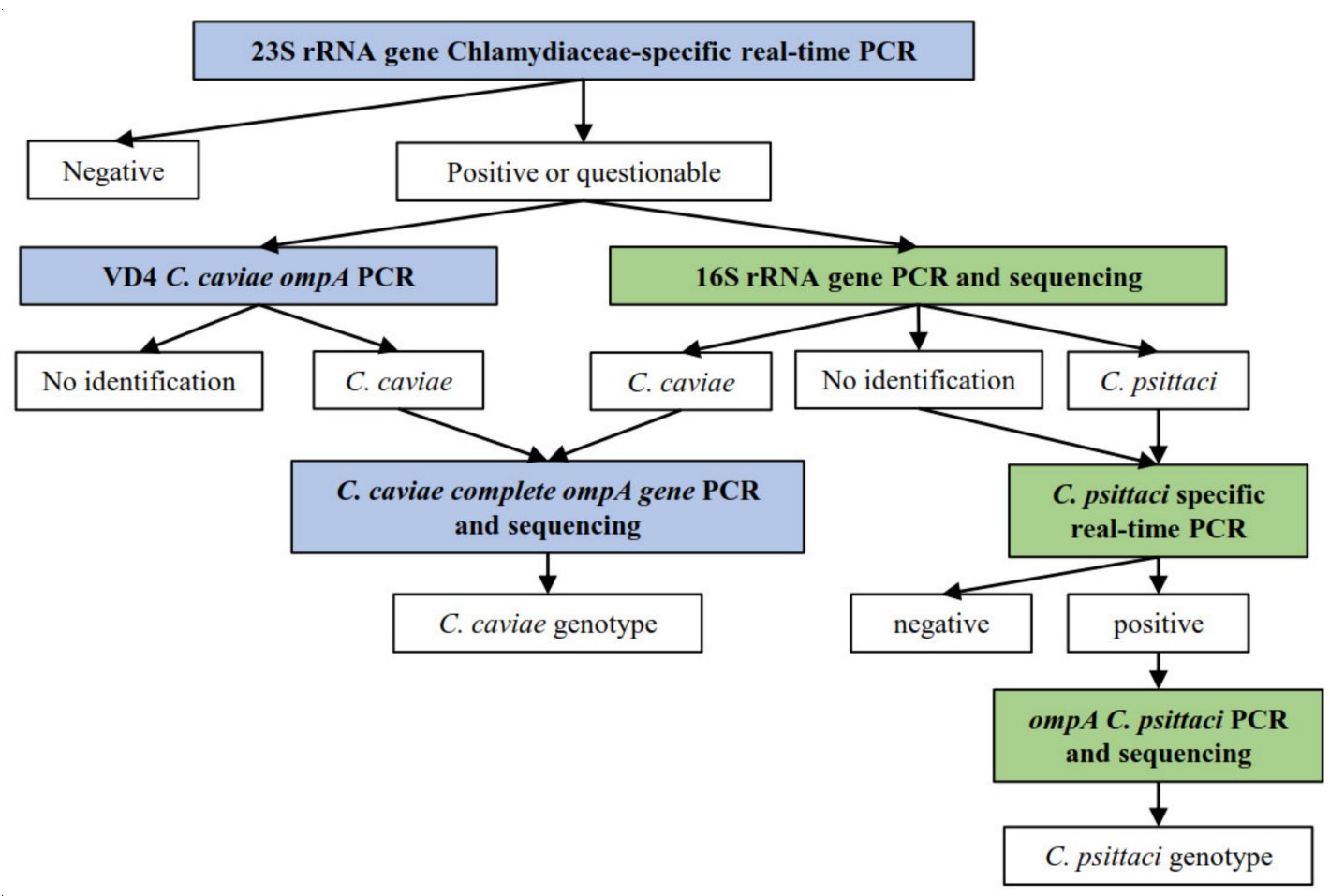

Figure 4. Decision tree for the sample processing, according to the different methods applied in each country, in which displays the methods applied only for the Swiss sample set, whereas $\square$ displays the methods applied on both Dutch and Swiss sample set. $\square$ depicts the results obtained for each method. 


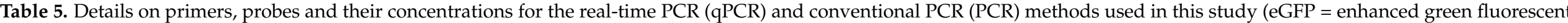
protein, IPC = internal positive control, ompA = outer membrane protein A).

\begin{tabular}{|c|c|c|c|c|c|c|c|}
\hline Method & Target & Primer and Probe & Sequence $\left(5^{\prime}-3^{\prime}\right)$ & $\begin{array}{l}\text { Final Concentration of } \\
\text { Primers and Probe in } \\
\text { the PCR Mix }\end{array}$ & $\begin{array}{l}\text { Base Pairs } \\
\text { for Each } \\
\text { Amplicon }\end{array}$ & $\begin{array}{c}\text { Annealing } \\
\text { Temperature }\end{array}$ & References \\
\hline \multirow{3}{*}{$\begin{array}{c}\text { Chlamydiaceae } 23 \mathrm{~S} \text { rRNA } \\
\text { qPCR }^{1}\end{array}$} & $23 \mathrm{SRNA}^{1}$ & $\begin{array}{l}\text { Ch23S-F } \\
\text { Ch23S-R } \\
\text { Ch23S-p }\end{array}$ & $\begin{array}{c}\text { CTGAAACCAGTAGCTTATAAGGGGT } \\
\text { ACCTCGCCGTTTAACTTAACTCC } \\
\text { FAM-CTCATCATGCAAAAGGCACGCCG-TAMRA }\end{array}$ & $\begin{array}{l}500 \mathrm{nM}^{\mathrm{A}} / 1000 \mathrm{nM}^{\mathrm{B}} \\
200 \mathrm{nM}\end{array}$ & 111 & $60^{\circ} \mathrm{C}$ & [34] \\
\hline & $\mathrm{eGFP}^{3}$ & $\begin{array}{l}\text { eGFP-1-F } \\
\text { eGFP-10-R } \\
\text { eGFP-Hex }\end{array}$ & $\begin{array}{c}\text { GACCACTACCAGCAGAACAC } \\
\text { CTTGTACAGCTCGTACATGC } \\
\text { HEX-AGCACCCAGTCCGCCCTGAGCA-BHQI }\end{array}$ & $200 \mathrm{nM}$ & 177 & & [35] \\
\hline & $\mathrm{IPC}^{2}$ & $\begin{array}{l}\text { ChMIX3IPC-template } \\
\text { (plasmid) } \\
\text { IPC-probe }\end{array}$ & $\begin{array}{c}\text { ACCTCGCCGTTTAACTTAACTCCCTGCGCGGATGCTA } \\
\text { ATGGCACAAGCGCGTCGTTCGTACCTAGAAGGTTTG } \\
\text { AAGCACCTT CCCACATAGTGACCGCTTATAAGC- } \\
\text { TACTGGTTTCAG } \\
\text { VIC-CGCGTCGTTCGTACC-MGB-NFQ }\end{array}$ & $200 \mathrm{nM}$ & & & In-house \\
\hline $16 \mathrm{~S}$ rRNA PCR ${ }^{3}$ & 16S rRNA & $\begin{array}{l}\text { 16S IGF } \\
\text { 16S IGR }\end{array}$ & $\begin{array}{l}\text { GATGAGGCATGCAAGTCGAACG } \\
\text { CCAGTGTTGGCGGTCAATCTCTC }\end{array}$ & $300 \mathrm{nM}$ & 278 & $58^{\circ} \mathrm{C}$ & [37] \\
\hline VD4 C. caviae omp $A \mathrm{PCR}^{1}$ & $\begin{array}{l}\text { VD4 of the } o m p A \\
\text { gene }\end{array}$ & $\begin{array}{l}\text { CCVDF } \\
\text { CCVDR }\end{array}$ & $\begin{array}{c}\text { GTCCAGAGCTACATTTGATGC } \\
\text { ATTTTGTTGATTTGAAGCGAAGC }\end{array}$ & $500 \mathrm{nM}$ & 130 & $60^{\circ} \mathrm{C}$ & [38] \\
\hline \multirow{2}{*}{ C. psittaci-specific qPCR ${ }^{3}$} & ompA & $\begin{array}{l}\text { CppsOMP1_For } \\
\text { CppsOMP1_Rev } \\
\text { CppsOMP1 }\end{array}$ & $\begin{array}{c}\text { CACTATGTGGGAAGGTGCTTCA } \\
\text { CTGCGCGGATGCTAATGG } \\
\text { FAM-CGCTACTTGGTGTGAC-MGB-NFQ }\end{array}$ & $\begin{array}{l}900 \mathrm{nM} \\
200 \mathrm{nM}\end{array}$ & 76 & $60^{\circ} \mathrm{C}$ & [39] \\
\hline & eGFP & $\begin{array}{l}\text { eGFP_For } \\
\text { eGFP_Rev } \\
\text { eGFP_probe }\end{array}$ & $\begin{array}{l}\text { GACCACTACCAGCAGAACAC } \\
\text { GAACTCCAGCAGGACCATG } \\
\text { AGCACCCAGTCCGCCCTGAGCA }\end{array}$ & $\begin{array}{l}400 \mathrm{nM} \\
200 \mathrm{nM}\end{array}$ & 132 & & [35] \\
\hline $\begin{array}{c}\text { OmpA C. psittaci-specific } \\
\text { PCR }^{3}\end{array}$ & ompA & $\begin{array}{l}\text { ompA F (CTU) } \\
\text { ompA rev }\end{array}$ & $\begin{array}{l}\text { ATGAAAAAACTCTTGAAATCGG } \\
\text { TCCTTAGAATCTGAATTGAGC }\end{array}$ & $200 \mathrm{nM}$ & 1050 & $49^{\circ} \mathrm{C}$ & [40] \\
\hline \multirow{2}{*}{$\begin{array}{l}\text { C. caviae complete ompA } \\
{\text { gene } \mathrm{PCR}^{1}}^{1}\end{array}$} & ompA & $\begin{array}{l}\text { ompA_Fw1 } \\
\text { ompA_Rv1 }\end{array}$ & $\begin{array}{l}\text { GAATAGCGAGCACAAAAAGAAAAGA } \\
\text { GGTTCTGATAGCGGGACAAAAA }\end{array}$ & $500 \mathrm{nM}^{\mathrm{A}} / 400 \mathrm{nM}^{\mathrm{B}}$ & 1268 & $\begin{array}{l}59^{\circ} \mathrm{C}^{\mathrm{A}} \\
60^{\circ} \mathrm{C}^{\mathrm{B}}\end{array}$ & \multirow{2}{*}{ [8] } \\
\hline & Additional primers & $\begin{array}{l}\text { ompA_Fw3 } \\
\text { ompA_Rv3 }\end{array}$ & $\begin{array}{c}\text { GCAGAATGGTCCACAAAT\#GC } \\
\text { GTTCAATCTATAAGAAAGAGCTAAAC }\end{array}$ & $500 \mathrm{nM}$ & 498 & & \\
\hline
\end{tabular}

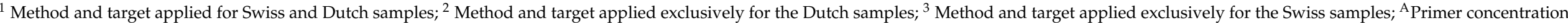

and annealing temperature applied for the Swiss methods; ${ }^{\mathrm{B}}$ Primer concentration and annealing temperature applied for the Dutch methods. 
All positive or questionable Swiss samples in the 23S rRNA Chlamydiaceae-specific real-time PCR were further investigated by the $16 \mathrm{~S}$ rRNA conventional PCR [37]. A short fragment of 278 base pairs in the conserved $16 S$ gene was targeted. Primers $16 S$ IGF and 16S IGR were used. C. suis DNA and molecular grade water were added to each run as positive and negative controls, respectively. Cycling was performed on the Thermocycler Biometra TProfessional Trio (Labgene Scientific, Switzerland) and each PCR product was confirmed for correct product length by gel electrophoresis on a 1.5\% agarose gel plus GelRed®Nucleid Acid Stain (Biotium, California, USA), which ran for 45 min at $100 \mathrm{~V}$ and $400 \mathrm{~mA}$. A $100 \mathrm{bp}$ GeneRuler DNA Ladder (Thermo Scientific, Vantaa, Finland) was loaded and each sample dyed with $6 \times$ DNA Loading Dye (Thermo Scientific, Vantaa, Finland). PCR products were then viewed using BioDoc-It ${ }^{2} 220$ Imaging System (UVP, Cambridge, United Kingdom) and positive templates in either length were purified using the GeneJET PCR Purification Kit (Thermo Fisher Scientific, Waltham, MA, USA) following manufacturer's instructions. Purified samples were Sanger-sequenced by Microsynth. Sequences were then assembled and evaluated using Geneious Software (Version 2021.0.1, available online: https:/ / www.geneious.com, accessed from March to May 2021) and compared against sequences in the NCBI database using the BLASTn tool (Available online: https: / / blast.ncbi.nlm.nih.gov/, accessed from March to May 2021).

All Dutch samples with Ct values $<40$ and inconclusive Swiss samples in the Chlamydiaceae 23S rRNA real-time PCR were further analyzed by means of a conventional PCR targeting the variable domain 4 of the C. caviae ompA gene [38]. Primers CCVDF and CCVDR were used to target a 130 base pairs amplicon. Reactions ran on the Stratagene MX3005P qPCR system (Applied Biosystems, Waltham, MA, USA). PCR products of samples with a melting curve with a Tm between $79{ }^{\circ} \mathrm{C}$ and $83{ }^{\circ} \mathrm{C}$ were forwarded for Sanger-sequencing by Baseclear BV (Leiden, The Netherlands). Sequences were then aligned using the Sequencer 4.10.1 and compared against available $C$. caviae sequences from the NCBI database.

\subsection{Typing of C. psittaci-Positive Swiss Samples}

To assess all Chlamydiaceae-positive Swiss samples for the zoonotic chlamydial species C. psittaci, a C. psittaci-specific qPCR was performed according to Pantchev et al. [39]. The target product consists of an amplicon of 76 base pairs and the qPCR includes an internal positive control (eGFP) [35]. The PCR consisted of primers CppsOMP1_For, CppsOMP1_Rev and probe CppsOMP1 as well as eGFP_For, eGFP_Rev and probe eGFP_probe. All samples ran in duplicate on the QuantStudio 5 and Applied Biosystems ${ }^{\mathrm{TM}} 7500$ RealTime PCR System (Thermo Fisher Scientific, Switzerland). Synthesized oligonucleotide of the ompA gene of C. psittaci and molecular grade water were added in each run as positive and negative controls, respectively. Samples were considered positive when a Ct value was generated.

All C. psittaci-positive samples were further investigated by using a C. psittaci ompA PCR as described by Sachse et al. [40], which targets a 1050 base pair amplicon. Primers ompA F (CTU) and ompA rev were used and the PCR ran on the Thermocycler Biometra TProfessional Trio (Labgene Scientific, Châtel-Saint-Denis, Switzerland). Additionally, a positive (C. psittaci T49/90) and a negative control (molecular grade water) were added in each run. Gel electrophoresis and sequencing was performed as previously described.

\subsection{OmpA Typing of C. caviae-Positive Swiss and Dutch Samples}

All confirmed C. caviae positive Swiss and Dutch samples in this study $(\mathrm{n}=27)$ were evaluated by a C. caviae-specific PCR based on the complete ompA gene, as described by Ramakers et al. [8]. Additionally, 37 positive conjunctival samples originating from the previous Swiss study on C. caviae prevalence in guinea pigs were added to the sample set [6]. All C. caviae complete ompA sequences were assembled and analyzed using Sequencher 4.10.1. Sequences were then compared against the sequence of the C. caviae GPIC reference strain and NL_Conj_Li (Genbank accession numbers: AE015925.1, KY777661.1). 
A maximum-likelihood tree of ompA sequences was calculated using MEGA 7.0.26 and visualized using Grapetree (1.5.0).

\subsection{Whole Genome Sequencing}

C. caviae isolates NL_Conj_Li and 04DC41 were cultured using Buffalo Green Monkey (BGM) cells as previously described [41]. C. caviae NL_Conj_Li was originally isolated from a conjunctival swab of a Dutch guinea pig that was related to the zoonotic case in 2014 [8]. C. caviae $04 \mathrm{DC} 41$ was originally isolated from a lung tissue of a guinea pig in Germany in 2014 (personal communication, C. Schnee). Genomic DNA was extracted using the DNeasy Blood and Tissue kit (Qiagen GmbH, Hilden, Germany) according to the manufacturer's protocol, but with an additional incubation step of $10 \mathrm{~min}$ at $70^{\circ} \mathrm{C}$ after addition of buffer AL. Whole genome sequencing of the Dutch zoonotic isolate NL_Conj_Li was performed on DNA of the third passage with Illumina sequencing. The passage number of the German isolate 04DC41 was unknown. Genomic DNA of isolates NL_Conj_Li and 04DC41 was prepared for sequencing on the Illumina MiSeq PE250 platform using the TruSeq kit (Illumina, San Diego, CA, USA) according to the manufacturer's protocol. Illumina reads were adapter-filtered and quality-filtered using BBDuk (BBMap suite, 38.79) and filtered against the Macaca mulatta genome (Reference sequence: GCF_000772875) to remove any reads from the host cells before assembly, using Bowtie2. Filtered data was assembled using SPAdes (v3.8.0) [42]. DNA of isolate NL_Conj_Li was also used for long-read sequencing to generate a fully closed genome. To close the genome of NL_Conj_Li, sequencing was repeated with Oxford Nanopore on DNA of the fifth passage. A sequencing library was prepared using Ligation sequencing kit SQK-LSK-109 and sequenced on flowcell type FLO-MIN106D in the MinION Mk1-b, according to the manufacturer's protocol. Hybrid assembly was performed using Unicycler (v0.4.6) [43]. Annotation of the genomes was generated with Prokka (v1.14.6) [44].

\section{Conclusions}

To conclude, we found a lower $C$. caviae prevalence than had previously been assumed, with $2.7 \%(7 / 260)$ and $8.9 \%(78 / 878)$ in guinea pigs, originating from $6.6 \%(2 / 30)$ and $8.1 \%$ $(3 / 37)$ of husbandries in Switzerland and in The Netherlands, respectively. Genotyping of the complete ompA gene of $C$. caviae showed that all Dutch and Swiss sequences were sharing $100 \%$ nucleotide identity with the isolated strains from a Dutch patient during a zoonotic transmission from its guinea pig, but different from the C. caviae GPIC reference strain. These results might suggest the presence of one circulating strain in the European guinea pig population, that can potentially cause zoonotic transmission.

The majority $(88.2 \%(75 / 85))$ of all C. caviae-positive guinea pigs were asymptomatic, which might lead to unnoticed infections and a rapid spread of the pathogen within one husbandry. No C. caviae was detected in rabbits, but C. psittaci was identified in conjunctival samples from rabbits and rectal samples from guinea pigs. None of the owners displayed severe respiratory signs at the time of sampling. Nevertheless, our results raise concerns about another zoonotic chlamydial strain present in these two animal species and the possibility of novel host species harboring C. psittaci. Therefore, caution and general hygiene measures should be applied when handling rodents and lagomorphs, especially if these are exhibiting typical Chlamydia-related clinical signs.

Supplementary Materials: The following are available online at https:/ / www.mdpi.com/article / 10.3390/pathogens10101230/s1, Table S1: Details on sample identity, diagnostics performed and subsequent results of each conjunctival and rectal swab sampled in Switzerland (qPCR: real-time PCR; PCR: conventional PCR). Table S2: Details on sample identity, diagnostics performed, and subsequent results of each conjunctival composite swab sampled in The Netherlands (qPCR: real-time PCR; PCR: conventional PCR). Table S3: Sequence comparison of specific genes of interest between strain NL_Conj_Li to strains 04DC41 and GPIC. Table S4: Content of each reaction mix and cycling protocols for the different real-time PCR (qPCR) and conventional PCR (PCR) methods used in this study. 
Author Contributions: Conceptualization, S.C., M.H., M.S.M.B., M.M.d.G., J.S., J.-M.H. and N.B.; data curation, S.C., M.M.d.G., A.B., B.P. and M.H.; funding acquisition, N.B., M.H. and Y.v.Z.; investigation, S.C., M.S.M.B., M.M.d.G., Y.v.Z., A.B., B.P., J.S., M.H. and N.B.; methodology, S.C., M.S.M.B., M.M.d.G., Y.v.Z., A.B., B.P., J.S., M.H. and N.B.; project administration, M.H. and N.B.; resources, Y.v.Z., M.H. and N.B.; supervision, M.S.M.B., Y.v.Z., J.-M.H., M.H. and N.B.; validation, M.S.M.B., M.H. and N.B.; visualization, S.C.; writing-original draft, S.C. and M.S.M.B.; writingreview \& editing, M.M.d.G., Y.v.Z., A.B., B.P., J.S., J.-M.H., M.H. and N.B. All authors have read and agreed to the published version of the manuscript.

Funding: This study was partially supported by the Dutch Ministry of Agriculture, Nature and the Environment (grant WOT-01-002-005.02) (granted to M.H.) and the Dutch Society for the Protection of Animals (granted to Y.v.Z.).

Institutional Review Board Statement: This study was approved by the Cantonal Veterinary Office Zurich (Switzerland), animal experimentation permit No. ZH129/2019.

Data Availability Statement: All data supporting reported results are contained in the manuscript and the Supplementary Materials and are available on the server of the Institute of Veterinary Pathology.

Acknowledgments: We are grateful for the excellent technical assistance of Theresa Pesch, Brigitte Sigrist, Lea Rohner, Frank Harders, Arie Kant, Robin Ruuls, Marianne Vahl and Jan Priem. Furthermore, we would like to thank Hanna Marti for her intellectual contribution to this project. All breeders and helpers are thanked for their time and providing the animals. The laboratory work was performed partly using the logistics of the Center for Clinical Studies at the Vetsuisse Faculty of the University of Zurich. Additionally, we would like to thank Kleindier Liefhebbers Nederland, in particular Harry Arts, for their help in approaching guinea pig breeders in The Netherlands. The Dierenbescherming is thanked for supporting this study financially. We also thank Daisy Vanrompay from Ghent University, Belgium for the initial isolation of C. caviae NL_Conj_Li and Christiane Schnee from the Friedrich Loeffler Institute in Jena, Germany for providing C. caviae strain 04DC41 including additional information about the origin of the strain. Furthermore, we would like to acknowledge Yvonne Pannekoek from the Amsterdam UMC, University of Amsterdam, The Netherlands and Alexander Umanets (at that time affiliated to Wageningen Bioveterinary Research, Lelystad, The Netherlands) for initial MLST analysis of C. caviae in the Chlamydiales PubMLST database. Available online: http:/ / pubmLst.org/chlamydiales (accessed on 5 August 2021).

Conflicts of Interest: The authors declare no conflict of interest.

\section{References}

1. Borel, N.; Polkinghorne, A.; Pospischil, A. A Review on Chlamydial Diseases in Animals: Still a Challenge for Pathologists? Veter. Pathol. 2018, 55, 374-390. [CrossRef] [PubMed]

2. Burnard, D.; Polkinghorne, A. Chlamydial infections in wildlife-conservation threats and/or reservoirs of 'spill-over' infections? Veter. Microbiol. 2016, 196, 78-84. [CrossRef] [PubMed]

3. Murray, E.S. Guinea Pig Inclusion Conjunctivitis Virus: I. Isolation and Identification as a Member of the PsittacosisLymphogranuloma-trachoma Group. J. Infect. Dis. 1964, 114, 1-12. [CrossRef]

4. McGeoch, D.J. Molecular evolution of the $\gamma$-Herpesvirinae. Philos. Trans. R. Soc. B Biol. Sci. 2001, 356, 421-435. [CrossRef] [PubMed]

5. Mount, D.T.; Bigazzi, P.E.; Barron, A.L. Infection of Genital Tract and Transmission of Ocular Infection to Newborns by the Agent of Guinea Pig Inclusion Conjunctivitis. Infect. Immun. 1972, 5, 921-926. [CrossRef] [PubMed]

6. Lutz-Wohlgroth, L.; Becker, A.; Brugnera, E.; Huat, Z.L.; Zimmermann, D.; Grimm, F.; Haessig, M.; Greub, G.; Kaps, S.; Spiess, B.; et al. Chlamydiales in Guinea-pigs and Their Zoonotic Potential. J. Veter. Med. Ser. A 2006, 53, 185-193. [CrossRef]

7. Cheong, H.C.; Lee, C.Y.Q.; Cheok, Y.Y.; Tan, G.M.Y.; Looi, C.Y.; Wong, W.F. Chlamydiaceae: Diseases in Primary Hosts and Zoonosis. Microorganisms 2019, 7, 146. [CrossRef]

8. Ramakers, B.P.; Heijne, M.; Lie, N.; Le, T.-N.; Van Vliet, M.; Claessen, V.P.; Tolsma, P.J.; De Rosa, M.; Roest, H.I.; Vanrompay, D.; et al. Zoonotic Chlamydia caviae Presenting as Community-Acquired Pneumonia. N. Engl. J. Med. 2017, 377, 992-994. [CrossRef]

9. Van Grootveld, R.; Bilsen, M.P.; Boelsums, T.L.; Heddema, E.R.; Groeneveld, G.H.; Gooskens, J.; De Boer, M.G. Chlamydia caviae Causing Community-Acquired Pneumonia: An Emerging Zoonosis. Vector-Borne Zoonotic Dis. 2018, 18, 635-637. [CrossRef]

10. Harrup, A.J.; Rooney, N. Current welfare state of pet guinea pigs in the UK. Veter. Rec. 2020, 186, 282. [CrossRef]

11. Fawcett, A. Management of husbandry-related problems in guinea pigs. In Pract. 2011, 33, 163-171. [CrossRef]

12. Spalatin, J.; Fraser, C.E.O.; Connell, R.; Hanson, R.P.; Berman, D.T. Agents of psittacosis-lymphogranuloma venereum group isolated from muskrats and snowshoe hares in Saskatchewan. Can. J. Comp. Med. Veter. Sci. 1966, 30, $260-264$. 
13. Iversen, J.O.; Spalatin, J.; Fraser, C.E.O.; Hanson, R.P.; Berman, D.T. The Susceptibility of Muskrats and Snowshoe Hares to Experimental Infection with a Chlamydial Agent. Can. J. Comp. Med. Rev. Can. Med. Comp. 1970, 34, 80-89.

14. Iversen, J.O.; Spalatin, J.; Fraser, C.E.O.; Hanson, R.P. Ocular involvement with chlamydia psittaci (Strain M56) in rab-bits inoculated intravenously. Can. J. Comp. Med. 1974, 38, 298-302. [PubMed]

15. Iversen, J.O.; Spalatin, J.; Hanson, R.P. Experimental chlamydiosis in wild and domestic lagomorphs. J. Wildl. Dis. 1976, 12, 215-220. [CrossRef]

16. Ni, X.; Qin, S.; Lou, Z.; Ning, H.; Sun, X. Seroprevalence and Risk Factors ofChlamydiaInfection in Domestic Rabbits (Oryctolagus cuniculus) in China. BioMed Res. Int. 2015, 2015, 1-5. [CrossRef] [PubMed]

17. Kilpatrick, A.M.; Altizer, S. Disease Ecology. Nat. Educ. Knowl. 2010, 3, 55.

18. Vanrompay, D.; Butaye, P.; Sayada, C.; Ducatelle, R.; Haesebrouck, F. Characterization of avian Chlamydia psittaci strains using omp1 restriction mapping and serovar-specific monoclonal antibodies. Res. Microbiol. 1997, 148, 327-333. [CrossRef]

19. Broecke, B.V.; Mariën, J.; Sabuni, C.A.; Mnyone, L.; Massawe, A.W.; Matthysen, E.; Leirs, H. Relationship between population density and viral infection: A role for personality? Ecol. Evol. 2019, 9, 10213-10224. [CrossRef]

20. Brunelle, B.W.; Sensabaugh, G.F. The ompA Gene in Chlamydia trachomatis Differs in Phylogeny and Rate of Evolution from Other Regions of the Genome. Infect. Immun. 2006, 74, 578-585. [CrossRef]

21. Rawre, J.; Juyal, D.; Dhawan, B. Molecular Typing of Chlamydia trachomatis: An Overview. Indian J. Med Microbiol. 2017, 35, 17-26. [CrossRef]

22. Pannekoek, Y.; Dickx, V.; Beeckman, D.S.A.; Jolley, K.A.; Keijzers, W.C.; Vretou, E.; Maiden, M.C.J.; Vanrompay, D.; Van Der Ende, A. Multi Locus Sequence Typing of Chlamydia Reveals an Association between Chlamydia psittaci Genotypes and Host Species. PLoS ONE 2010, 5, e14179. [CrossRef]

23. Overgaauw, P.; Avermaete, K.; Mertens, C.; Meijer, M.; Schoemaker, N. Prevalence and zoonotic risks of Trichophyton mentagrophytes and Cheyletiella spp. in guinea pigs and rabbits in Dutch pet shops. Veter. Microbiol. 2017, 205, 106-109. [CrossRef]

24. Harkinezhad, T.; Geens, T.; Vanrompay, D. Chlamydophila psittaci infections in birds: A review with emphasis on zoonotic consequences. Veter. Microbiol. 2009, 135, 68-77. [CrossRef] [PubMed]

25. Sanderson, H.; Vasquez, M.; Killion, H.; Vance, M.; Sondgeroth, K.; Fox, J. Fatal Chlamydia psittaci infection in a domestic kitten. J. Veter. Diagn. Investig. 2021, 33, 101-103. [CrossRef] [PubMed]

26. Sprague, L.D.; Schubert, E.; Hotzel, H.; Scharf, S.; Sachse, K. The detection of Chlamydophila psittaci genotype C infection in dogs. Veter. J. 2009, 181, 274-279. [CrossRef]

27. Jenkins, C.; Jelocnik, M.; Melinda, L.; O’Rourke, B.; Chicken, C.; Carrick, J.; Polkinghorne, A. An epizootic of Chlamydia psittaci equine reproductive loss associated with suspected spillover from native Australian parrots. Emerg. Microbes Infect. 2018, 7, 1-13. [CrossRef] [PubMed]

28. Reinhold, P.; Ostermann, C.; Liebler-Tenorio, E.; Berndt, A.; Vogel, A.; Lambertz, J.; Rothe, M.; Rüttger, A.; Schubert, E.; Sachse, K. A Bovine Model of Respiratory Chlamydia psittaci Infection: Challenge Dose Titration. PLoS ONE 2012, 7, e30125. [CrossRef] [PubMed]

29. Knittler, M.R.; Sachse, K. Chlamydia psittaci: Update on an underestimated zoonotic agent. Pathog. Dis. 2015, 73, 1-15. [CrossRef] [PubMed]

30. Hogerwerf, L.; Roof, I.; De Jong, M.J.K.; Dijkstra, F.; Van Der Hoek, W. Animal sources for zoonotic transmission of psittacosis: A systematic review. BMC Infect. Dis. 2020, 20, 1-14. [CrossRef] [PubMed]

31. Favaroni, A.; Trinks, A.; Weber, M.; Hegemann, J.H.; Schnee, C. Pmp Repertoires Influence the Different Infectious Potential of Avian and Mammalian Chlamydia psittaci Strains. Front. Microbiol. 2021, 12, 1-13. [CrossRef]

32. Chan, J.; Doyle, B.; Branley, J.; Sheppeard, V.; Gabor, M.; Viney, K.; Quinn, H.; Janover, O.; McCready, M.; Heller, J. An outbreak of psittacosis at a veterinary school demonstrating a novel source of infection. One Health 2017, 3, 29-33. [CrossRef]

33. Jelocnik, M.; Branley, J.; Heller, J.; Alderson, S.; Galea, F.; Polkinghorne, A. Multilocus sequence typing identifies an avian-like Chlamydia psittaci strain involved in equine placentitis and associated with subsequent human psittacosis. Emerg. Microbes Infect. 2017, 6, 1-3. [CrossRef]

34. Ehricht, R.; Slickers, P.; Goellner, S.; Hotzel, H.; Sachse, K. Optimized DNA microarray assay allows detection and genotyping of single PCR-amplifiable target copies. Mol. Cell. Probes 2006, 20, 60-63. [CrossRef] [PubMed]

35. Hoffmann, B.; Depner, K.; Schirrmeier, H.; Beer, M. A universal heterologous internal control system for duplex real-time RT-PCR assays used in a detection system for pestiviruses. J. Virol. Methods 2006, 136, 200-209. [CrossRef]

36. Heijne, M.; Van Der Goot, J.A.; Fijten, H.; Van Der Giessen, J.W.; Kuijt, E.; Maassen, C.B.M.; Van Roon, A.; Wit, B.; Koets, A.P.; Roest, H.I.J. A cross sectional study on Dutch layer farms to investigate the prevalence and potential risk factors for different Chlamydia species. PLoS ONE 2018, 13, e0190774. [CrossRef]

37. Taylor-Brown, A.; Vaughan, L.; Greub, G.; Timms, P.; Polkinghorne, A. Twenty years of research into Chlamydia-like organisms: A revolution in our understanding of the biology and pathogenicity of members of the phylum Chlamydiae. Pathog. Dis. 2015, 73, 1-15. [CrossRef] [PubMed]

38. Heddema, E.R.; Van Hannen, E.J.; Bongaerts, M.; Dijkstra, F.; Hove, R.-J.T.; De Wever, B.; Vanrompay, D. Typing of Chlamydia psittaci to monitor epidemiology of psittacosis and aid disease control in The Netherlands, 2008 to 2013. Eurosurveillance 2015, 20, 21026. [CrossRef] 
39. Pantchev, A.; Sting, R.; Bauerfeind, R.; Tyczka, J.; Sachse, K. New real-time PCR tests for species-specific detection of Chlamydophila psittaci and Chlamydophila abortus from tissue samples. Veter. J. 2009, 181, 145-150. [CrossRef] [PubMed]

40. Sachse, K.; Laroucau, K.; Hotzel, H.; Schubert, E.; Ehricht, R.; Slickers, P. Genotyping of Chlamydophila psittaci using a new DNA microarray assay based on sequence analysis of ompA genes. BMC Microbiol. 2008, 8, 63. [CrossRef] [PubMed]

41. Kik, M.; Heijne, M.; Ijzer, J.; Grinwis, G.; Pannekoek, Y.; Gröne, A. Fatal Chlamydia avium Infection in Captive Picazuro Pigeons, The Netherlands. Emerg. Infect. Dis. 2020, 26, 2520-2522. [CrossRef]

42. Antipov, D.; Korobeynikov, A.; McLean, J.S.; Pevzner, P.A. hybridSPAdes: An algorithm for hybrid assembly of short and long reads. Bioinformatics 2016, 32, 1009-1015. [CrossRef] [PubMed]

43. Wick, R.R.; Judd, L.M.; Gorrie, C.L.; Holt, K.E. Unicycler: Resolving bacterial genome assemblies from short and long sequencing reads. PLoS Comput. Biol. 2017, 13, e1005595. [CrossRef] [PubMed]

44. Seemann, T. Prokka: Rapid Prokaryotic Genome Annotation. Bioinformatics 2014, 30, 2068-2069. [CrossRef] [PubMed] 